\title{
11-Ketotestosterone and IGF-I increase the size of previtellogenic oocytes from shortfinned eel, Anguilla australis, in vitro
}

\author{
P Mark Lokman, Kataraina A N George, Sean L Divers, Michael Algie and Graham Young ${ }^{1}$ \\ Department of Zoology, University of Otago, 340 Great King Street, PO Box 56, Dunedin 9054, New Zealand and \\ ${ }^{1}$ School of Aquatic and Fishery Sciences, University of Washington, Seattle, Washington 98195, USA
}

Correspondence should be addressed to P M Lokman; Email: mark.lokman@stonebow.otago.ac.nz

\begin{abstract}
Previtellogenic ovarian fragments from eel, Anguilla australis, were cultured in vitro in a chemically defined medium containing steroids and/or peptide hormones for 18 days in order to investigate their involvement in control of early oocyte growth. 11-Ketotestosterone (11-KT), but not estradiol-17 $\beta$, induced a significant $10-20 \%$ increase in diameters of previtellogenic

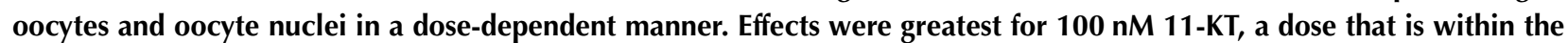
physiological range seen in very early vitellogenic eels in the wild. The effect was not accompanied by obvious ultrastructural changes in the oocytes other than an apparent increase in nuclear size. Similarly, treatment with recombinant human IGF-I resulted in increased oocyte diameters, whereas no such effect was seen after treatment with heterologous insulin, GH, leptin, or human chorionic gonadotropin. Interestingly, lipid supplementation also resulted in an increase in oocyte diameter, and greater radioactivity in ovarian explants following incubation with ${ }^{14} \mathrm{C}$-triglycerides and 11-KT, but not FSH, suggesting that the androgen may play a role in lipid accumulation into the oocyte. Our results implicate hormones from both the reproductive and the metabolic axes in control of previtellogenic oocyte growth in a teleost fish.

Reproduction (2007) 133 955-967
\end{abstract}

\section{Introduction}

The development of a fertilizable egg in oviparous vertebrates requires a substantial accumulation of nutritive resources for the development of the future embryo. Most of these resources are yolk proteins, which are laid down during vitellogenesis, the major growth phase known to be under gonadotropin and estrogen control (reviewed in Nagahama et al. 1995). Prior to the entry into vitellogenesis, oocytes from a typical teleost fish will have attained a 10- to 100-fold increase in diameter when compared with the oogonial stage. The oogonial stage is characterized by active proliferation of germ cells followed by their entry into the first meiotic division. In Japanese huchen (Hucho perryi), the steroid hormones estradiol-17 $\beta$ (E2) and 17,20ß-dihydroxy-4pregnen-3-one have been implicated in controlling oogonial proliferation and entry into meiosis respectively (Higashino et al. 2003). In contrast, very little information is available on the factors that regulate the previtellogenic or primary growth phase (Tyler et al. 2000, Patiño \& Sullivan 2002, Campbell et al. 2006), despite their potential importance in controlling oocyte recruitment, and hence, in governing egg batch size (fecundity) at spawning.

The role of pituitary hormones in previtellogenic oocyte growth is not clear; a recent study identified a peak of follicle-stimulating hormone (FSH) around the time of ovulation in rainbow trout, Oncorhynchus mykiss, and it was suggested that this peak may be related to the stimulation of development of a new batch of oocytes for spawning in the following year (Santos et al. 2001). Studies on coho salmon, Oncorhynchus kisutch, also deduced an important role for $\mathrm{FSH}$ in very early stages of oogenesis, well before estrogen-mediated vitellogenesis is initiated (Campbell et al. 2006). In contrast, many early studies on hypophysectomized teleost fish have failed to identify a clear role for pituitary hormones on previtellogenic oocytes in a number of fish species, such as catfish, Heteropneustes fossilis (Sundararaj \& Goswami 1968). A study by Khoo (1979) likewise indicated that previtellogenic growth may be pituitary independent in hypophysectomized goldfish, Carassius auratus. In very early vitellogenic 
silver eel, Anguilla anguilla, diameters of oocytes in hypophysectomized fish 2-3 weeks after surgery were slightly smaller than those of controls, but no other histological differences were apparent (Fontaine et al. 1976). It is possible that the effects of hypophysectomy on early stages of oogenesis were missed in these studies due to the seasonal absence of FSH or the focus on vitellogenic oocytes. Regardless, Khoo identified the apparent stimulatory effects of steroids, especially estrogens, on formation of cortical alveoli (Khoo 1979). More recently, prolonged treatment with 11-ketotestosterone (11-KT) in vivo was found to increase the size of previtellogenic oocytes in shortfinned eel, Anguilla australis (Rohr et al. 2001). However, the authors did not determine whether these androgen effects were direct or indirect (through feedback on the brain and/or pituitary). Organ culture may prove useful to address this issue, but few researchers have taken this approach for the study of oocyte growth. Among those who have a positive effect of testosterone on incubated vitellogenic ovarian tissue from goldfish was seen: the proportion of previtellogenic oocytes was higher after testosterone treatment than that in controls, while survival of vitellogenic oocytes was prolonged (Remacle et al. 1976). In mammals, spontaneous progression of primordial follicles to primary follicles maintained in vitro has been reported, and the presence of an inhibitory substance affecting this progression has been postulated (Fortune et al. 2000). Using in vivo models, androgens have recently been implicated in stimulating growth of primordial ovarian follicles (Vendola et al. 1999a). That these androgen effects are direct was supported by the presence of androgen receptors (ARs) in the ovary and clinical observations. Androgen effects appear to be mediated, at least in part, through insulin-like growth-factor-I (IGF-I), given the increase in both IGF-I and IGF-I receptor mRNA levels that occurred after androgen treatment (Vendola et al. 1999b). Other growth factors, such as growth and differentiation factor-9 (Nilsson \& Skinner 2002), kit-ligand/stem-cell factor (Parrott \& Skinner 1999) and fibroblast growth factor (Nilsson et al. 2001), and hormones from the growth axis, such as insulin (Kezele et al. 2002) may also play a role throughout the development of mammalian ovarian follicles. Crosstalk between the metabolic/ nutritional and reproductive systems is likely to operate also in fishes, as there is ample evidence that nutritional status affects oocyte recruitment and fecundity for a range of species (Tyler \& Sumpter 1996). A role for IGF-I in such crosstalk is probable (Campbell et al. 2006).

In vitro approaches have previously proven extremely valuable model systems for assessing hormonal control of spermatogenesis in eels, Anguilla japonica
(Miura et al. 1991). Because of the paucity of data on factors controlling previtellogenic growth in teleost fishes and their potential involvement in controlling fecundity, we used a long-term ovarian explant culture system to determine the direct effects of steroids (11-KT, E2) and peptide hormones (gonadotropin, growth hormone, leptin, IGF-I, and insulin) on growth of shortfinned eel previtellogenic ovarian follicles. Trials were repeated several times to ensure that responses were robust and assess whether they were affected by histological protocol. The robust and significant effects of 11-KT prompted follow-up studies aimed at assessing the effects of 11-KT on lipid uptake and AR abundance in ovarian explants in vitro.

\section{Materials and Methods}

\section{Animals}

All eels used for experimentation were previtellogenic female shortfins (400-800 g) in the 'yellow stage' mostly obtained from commercial eel-processing companies. Animals were caught by fyke nets and held captive by commercial fishermen for a variable length of time (up to about 3 weeks) until their delivery to these processing companies. Female eels used in Trial IVB, reared to experimental size (500-1000 g) from the glass eels stage and kindly donated by Dr Peter Lee (NIWA, Auckland, New Zealand), were used after 1 week of arrival in the University of Otago facilities. Experiments were conducted in accordance with the guidelines of the University of Otago Animal Ethics Committee (protocols AEC 65-00 and ET 23-02).

\section{Biochemicals}

Steroids (11-KT, E2) were obtained from Steraloids (Newport, RI, USA) and Leibovitz L-15 medium from Sigma Chemical Co. Human chorionic gonadotropin (hCG; Lot CR127) and ovine growth hormone (oGH; NIH-oGH-15, Lot AFP9220A) were a gift from the National Institute of Health (NIH/NIDDK, Bethesda, MD, USA). Porcine and bovine insulin and recombinant human leptin (rhLEP; Lot 062K1603) were purchased from Sigma Chemical Co., while recombinant human IGF-I (rhIGF-I) was obtained from GroPep (Adelaide, Australia). Medium additives were purchased from Life Technologies (Gibco BRL: proline, aspartate), BDH (Poole, UK: glutamate), or Sigma (lipids, see Trial IV). Labeled triglyceride, [carbox$\mathrm{yl}-{ }^{14} \mathrm{C}$ ]triolein $(102 \mathrm{mCi} / \mathrm{mmol})$, was obtained from Perkin-Elmer (Wellesley, MA, USA). 


\section{Experiment I: in vitro effects of 11-KT or E2 on eel ovarian explants}

Trial IA

Three eels were purchased in August 2001 from Gould Aquafarms (Leeston, New Zealand) and euthanized in $0.3 \mathrm{~g} / \mathrm{l}$ benzocaine. Eels were bled and briefly submersed in $70 \%$ ethanol prior to the removal of ovaries under sterile conditions (Miura et al. 1991). Ovaries were placed in supplemented Leibovitz L-15 medium (suppL15) containing $10 \mathrm{mM}$ HEPES, $1.7 \mathrm{mM}$ L-proline, $0.1 \mathrm{mM}$ L-aspartic acid, and $0.1 \mathrm{mM}$ L-glutamic acid and, with scissors and forceps, cut into small fragments of 1-2 $\mathrm{mm}$ in each dimension (Miura et al. 1991).

Using 24-well Costar culture plates, fragments were incubated in $1 \mathrm{ml}$ suppL15 containing $0,1,10,100$, or $1000 \mathrm{ng} / \mathrm{ml} 11-\mathrm{KT}(\sim 3,30,300$, or $3000 \mathrm{nM}$ 11-KT; Steraloids). Porcine insulin (pINS, $1 \mathrm{mg} / \mathrm{l}$ ) was added to maintain tissue health as recommended for the eel testis explant culture system of Miura et al. (1991). Streptomycin sulfate $(0.1 \mathrm{~g} / \mathrm{l}$; Sigma Chemical Co.) and penicillin (100 $000 \mathrm{IU} / \mathrm{I}$; Sigma Chemical Co.) were added to inhibit bacterial growth. Attempts to float the tissue on elder pith, as described for eel testicular fragments (Miura et al. 1991) were unsuccessful and tissues were therefore submersed instead. Two replicate incubations were used for each treatment. Incubations were maintained for 18 days at $15^{\circ} \mathrm{C}$, the medium being changed every third day. At the end of experimentation, explants were processed using standard histological methods, embedded in paraffin, sectioned at $6 \mu \mathrm{m}$, and stained with hematoxylin and eosin. Images were analyzed for oocyte diameters as described in 'Image analysis' towards the end of this section.

\section{Trial IB}

Eels were obtained in November 2001 from Gould Aquafarms. For this trial, five eels that had served as placebo controls in the preceding week were used. These controls had been injected intraperitoneally $(1 \mathrm{ml} / \mathrm{kg}$ ) with a 50:50 mix of vegetable oil and vegetable shortening only and held in recirculating tanks at $16 \pm 0.5^{\circ} \mathrm{C}$ for 1 week. They were killed and processed for tissue culture as outlined under Trial IA.

Ovarian explants were exposed to $0,1,10,100$, or $1000 \mathrm{nM}$ of $11-\mathrm{KT}$ or E2 in suppL15 medium (340 mOsm) with $1 \mathrm{mg} / \mathrm{l}$ pINS and antibiotics added and maintained as described for Trial IA. Two replicate incubations were used for each treatment. Explants were preserved in Baker's calcium formol and processed for routine methacrylate sectioning at $2 \mu \mathrm{m}$ (Lokman et al. 1998).

\section{Trial IC}

In December 2002, three eels were acquired from a commercial fish exporting company (Ngai Tahu Fisheries, Dunedin, New Zealand). Fish were transferred to the laboratory and maintained in tanks supplied with recirculating water of $15 \pm 0.5^{\circ} \mathrm{C}$ for 1 week.

Eels were killed and dissected as before (Trials IA \& IB), and ovarian tissue incubated in single replicates at $15{ }^{\circ} \mathrm{C}$ for 18 days in suppL15 medium containing $1 \mathrm{mg} / \mathrm{l}$ pINS, $100 \mathrm{IU} / \mathrm{I}$ penicillin, and $1 \mathrm{mg} / \mathrm{l}$ streptomycin. $11-\mathrm{KT}$ was tested at doses of $0,1,10,100$, or $1000 \mathrm{nM}$. The zero dose was done in duplicate. Tissue handling was minimized by conducting the experiments in $1.5 \mathrm{ml}$ of suppL15 in 12-well culture plates and changing the medium every sixth, rather than every third day.

At the end of the trial, ovarian fragments were fixed in phosphate-buffered $(0.1 \mathrm{M}, \mathrm{pH} 7.4) 2.5 \%$ glutaraldehyde and postfixed in $1 \%$ phosphate-buffered $\mathrm{OsO}_{4}$ to prevent shrinkage of oocytes during processing. Tissues were then embedded in epoxy resin, sectioned at $2 \mu \mathrm{m}$, and stained with toluidine blue. In addition, ultrathin $80 \mathrm{~nm}$ sections were prepared from explants incubated with 0 or $100 \mathrm{nM} 11-\mathrm{KT}$ from each of the three eels, and viewed with a Philips CM100 transmission electron microscope to examine ultrastructural changes.

\section{Experiment II: in vitro effects of growth factors and pituitary hormones on eel ovarian fragments}

\section{Trial IIA}

This trial was conducted using ovarian tissue from the same eels as described under Trial IB above. Duplicate explants were incubated in suppL15 containing 0, 1, 30, or $1000 \mathrm{ng} / \mathrm{ml}$ oGH, hCG, pINS, or rhIGF-I. The cultures were maintained in the presence of $100 \mathrm{nM} 11-\mathrm{KT}$ (see effects of 11-KT in vitro in Trial IA, Results section) and antibiotics for 18 days at $16^{\circ} \mathrm{C}$, and the medium was changed every third day. Tissues were harvested, preserved, and processed as described for Trial IB.

\section{Trial IIB}

The effects of IGF-I were studied in more detail using a dose-response design with explants prepared from the eels described under Trial IC and using identical culture additives. Recombinant hIGF-I (1, 10, 100, and $1000 \mathrm{ng} / \mathrm{ml}$ ) dose-response treatments were done without replication, except for the controls $(0 \mathrm{ng} / \mathrm{ml} \mathrm{rhIGF}-\mathrm{I})$, which were done in duplicate. All cultures were supplemented with $100 \mathrm{nM} 11-\mathrm{KT}$. After incubation, explants were fixed as described under Trial IC and prepared for light microscopical observations. 


\section{Trial IIC}

A third trial with rh-IGF-I dose responses (0-1000 ng/ml) was conducted in September 2005. To assess whether IGF-I effects required the presence of androgen, cultures were set up for ovarian tissue from seven previtellogenic eels in suppL15, with or without addition of $100 \mathrm{nM}$ 11-KT. Replication was only between, not within, individual fish. Media, medium changes, and duration of the experiment were as described in Trial IC. Tissues were processed for routine embedding in methacrylate resin and oocyte diameters were determined by microscopy and image analysis (cf. Trial IB).

\section{Experiment III: in vitro effects of leptin on eel ovarian fragments}

\section{Trial IIIA}

Effects of rhLEP were investigated in February 2004 using the in vitro system validated above. A total of five previtellogenic eels were used, and ovarian tissue was incubated without replication according to Trial IA with or without leptin $(0-1000 \mathrm{ng} / \mathrm{ml})$ in the presence or

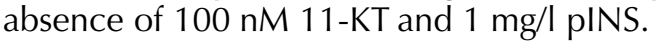

\section{Trial IIIB}

A replicate experiment with leptin was conducted a year later, using the same fish, incubation conditions, and evaluation protocols as described under Trial IIC. 11-KT was again used at $100 \mathrm{nM}$, whereas leptin was added as $0,1.25,12.5,125$, or $1250 \mathrm{ng} / \mathrm{ml}$. All single-run cultures were further supplemented with $1 \mathrm{mg} / \mathrm{l}$ bovine insulin.

\section{Experiment IV: effects of lipid supplementation on 11-KT-stimulated oocyte growth in vitro}

\section{Trial IVA in vitro accumulation of lipids}

Phospholipid (PL; 1,2-diacyl-sn-glycero-3-phosphocholine, Sigma Chemical Co.) or a fatty acid supplement (FAS) containing linoleic acid and oleic acid in BSA (Sigma Chemical Co.) were added to cultures of ovarian explants (same fish as used for Trial IIC) containing suppL15 and $1 \mathrm{mg} / \mathrm{l}$ bovine insulin. PL was added at $100 \mu \mathrm{g} / \mathrm{ml}$, and FAS at $60 \mathrm{ng} / \mathrm{ml}$ linoleic acid $+30 \mathrm{ng} / \mathrm{ml}$ oleic acid. Cultures were run without replication in the presence or absence of $11-\mathrm{KT}$ at $100 \mathrm{nM}$ for a total of 18 days and processed as described under Trial IIC.

\section{Trial IVB in vitro accumulation of ${ }^{14} \mathrm{C}$-triolein}

Ovarian tissue was recovered from five female eels in June 2006 as described for Trial I. For each female, tissue was placed on a piece of soft plastic and finely chopped with razor blades. Chopped tissue was divided into two approximately equal-sized portions. Portions were again equally divided, and so on, until a total of 16 approximately equal portions had been obtained. These were placed in wells of a 24-well plate and incubated in bovine insulin-supplemented L15 with or without $100 \mathrm{ng} / \mathrm{ml}$ native coho salmon FSH (kindly donated by Dr Penny Swanson, Northwest Fisheries Science Center, Seattle, WA, USA), and in the presence or absence of $100 \mathrm{nM} 11-\mathrm{KT}$. To all wells, $80 \mathrm{nCi}$ of [carboxyl- ${ }^{14} \mathrm{C}$ ]triolein was added, and duplicate incubations were accordingly set up for either 1 or 4 days. After incubation, the medium was aspirated off, and the tissue was washed with $1 \mathrm{ml}$ eel Ringer for $30 \mathrm{~min}$ at room temperature $\left(\mathrm{ca} 18^{\circ} \mathrm{C}\right.$ ) at $200 \mathrm{rpm}$. Washing was repeated once thereafter and as much as possible of the tissue was transferred to a plastic centrifuge tube. After any remaining medium was removed, the tissue was frozen at $-20{ }^{\circ} \mathrm{C}$ and subjected to three freeze-thaw cycles to burst cell membranes. Further cell lysis was achieved using $100 \mu \mathrm{l}$ proteinase $\mathrm{K}(10 \mathrm{mg} / \mathrm{ml}$ in TrisEDTA, $\mathrm{pH} \mathrm{7.5)}$ for $3 \mathrm{~h}$ at $37^{\circ} \mathrm{C}$. Sample volume was increased by addition of $100 \mu \mathrm{l} \mathrm{TE}$ buffer, and lysis completed by adding $100 \mu \mathrm{l}$ of $3 \mathrm{M} \mathrm{NaOH}$ and incubation at $65{ }^{\circ} \mathrm{C}$ for $2 \mathrm{~h}$. [Carboxyl- ${ }^{14} \mathrm{C}$ ]triolein accumulation was then estimated by scintillation counting (Wallac, Turku, Finland).

\section{Experiment V: in vitro effects of 11-KT on ovarian AR gene expression}

\section{Experimental design}

Ovarian tissue from five female eels was incubated with $0,1,10,100$, or $1000 \mathrm{ng} / \mathrm{ml} \mathrm{11-KT} \mathrm{as} \mathrm{described} \mathrm{in} \mathrm{Trial}$ IC. Tissue was harvested after 18 days, transferred to a plastic centrifuge tube, and flash-frozen in liquid nitrogen. Total RNA was extracted using Trizol Reagent (Invitrogen) and $1 \mu \mathrm{g}$ was reverse transcribed using random hexamer primers and Superscript III (Invitrogen). cDNAs were stored at $-80^{\circ} \mathrm{C}$ until analysis for mRNA levels by quantitative real-time PCR (QPCR).

\section{QPCR}

Four micrograms of total RNA, extracted from the testis of a silver-stage male shortfinned eel, was reverse transcribed using oligo-dT $\mathrm{dT}_{15-18}$ and Superscript III. Shortfinned eel $A R \alpha$ and $A R \beta$ cDNA fragments were obtained by PCR, with primer design guided by Genbank Accession Nos AB023960 and AB025361 respectively for the Japanese eel AR cDNAs. Primers used for AR $\alpha$ were forward 5'-TCCATGTTCCTCAACATCCTGGAG-3' and reverse 5'-GAAGTTCTTCATCCGGATGCAGTG-3', whereas AR $\beta$ CDNA was amplified using forward $5^{\prime}$-TCCACAAATCTTCCTTGTCTGAA- $3^{\prime}$ and reverse 5'-GGGTTTCAACTGTCCAATTTTCT-3'. PCR products of 360 and $374 \mathrm{bp}$ in length were obtained after 34 (AR $\alpha)$ or 31 (AR $\beta)$ cycles $\left(20 \mathrm{~s}\right.$ at $94{ }^{\circ} \mathrm{C}, 20 \mathrm{~s}$ at $58{ }^{\circ} \mathrm{C}$ and $30 \mathrm{~s}$ at 
$72{ }^{\circ} \mathrm{C}$ ) using Roche PCR reagents. PCR products were electrophoresed on agarose gels, excised using the QIAEX Gel Extraction Kit (Qiagen) and ligated into the pGEM T-Easy vector (Promega) according to the manufacturer's instructions. Following amplification in Escherichia coli XL-1 Blue and recovery of plasmid by Plasmid Midi Kit (Qiagen), cDNAs were sequenced and aligned with the Japanese eel homologs. Accordingly, 99.7 and $98.6 \%$ sequence identity was obtained at the nucleotide level for the $\alpha$ - and $\beta$-subtype respectively. At the amino acid level, both subtypes showed $100 \%$ sequence identity, confirming that the amplified fragments encoded the AR. cDNAs were recovered from the plasmid by restriction enzyme digestion, and standards $\left(10^{0}-10^{5}\right.$ copies/ $\left.\mu \mathrm{l}\right)$ generated for use in QPCR.

Primers for QPCR were designed with primer express as follows: AR $\alpha$ forward, 5'-GTACGTGGATGACCAGATGACAGT-3'; AR $\alpha$ reverse, 5'-CCAGCCCAGAGCGAACAC-3'; AR $\beta$ forward, 5'-AACGATTGCACCATTGATAAGCT-3'; AR $\beta$ reverse, 5'-CATTCCGGCCTCAAAGCA- $3^{\prime}$. Samples were heated for $2 \mathrm{~min}$ at $50^{\circ} \mathrm{C}$ and 2 min at $95{ }^{\circ} \mathrm{C}$ and then cycled 40 times between $95^{\circ} \mathrm{C}$ $(15 \mathrm{~s})$ and $58^{\circ} \mathrm{C}(30 \mathrm{~s})$ and $72{ }^{\circ} \mathrm{C}(30 \mathrm{~s})$, before a final extension step of $1 \mathrm{~min}$ at $72{ }^{\circ} \mathrm{C}$ using a Stratagene MX3000P Real Time thermal cycler. PCR products were subsequently subcloned into pGEM T-Easy vector and confirmation sequenced.

QPCR was carried out on duplicate samples of $50 \mathrm{ng}$ CDNA or on $1 \mu \mathrm{l}$ of standard using Invitrogen's SYBR Green qPCR Supermix in a reaction volume of $20 \mu \mathrm{l}$ on a single plate for each target. Primers were used at final concentrations of 400 (AR $\alpha$ reverse) or $800 \mathrm{nM}$ (other primers), determined on the basis of a primer dilution matrix. Amplicons were obtained as described in the previous paragraph. A melting curve was generated at the end of the run to ensure that only a single amplicon was amplified. MX-3000P (Stratagene, La Jolla, CA, USA) software generated standard curves and AR copy number estimates in each sample.

AR copy number was expressed per microgram of total RNA or normalized over copy number of elongation factor- $1 \alpha$ (ELF). For the latter approach, we amplified an ELF fragment by PCR using forward primer $5^{\prime}$ ATGGGAAAGGAAAAGATCCACATCA- $3^{\prime}$ and reverse primer $5^{\prime}$-TCAAGCTTCTTGCCAGAACGACGGT-3' at 25 cycles of denaturation $\left(94^{\circ} \mathrm{C}, 30 \mathrm{~s}\right)$, annealing $\left(52{ }^{\circ} \mathrm{C}, 30 \mathrm{~s}\right)$, and extension $\left(72{ }^{\circ} \mathrm{C}, 30 \mathrm{~s}\right)$. Primer design was based on the ELF sequence of zebrafish, Danio rerio (Accession No BC064291). An 1163 bp cDNA, located within the open reading frame, was cloned into the pGEM T-Easy plasmid vector and sequenced, as described for AR above. The sequence had 88.4 and $94.8 \%$ sequence identity with the zebrafish cDNA and deduced amino acid sequences respectively.

Plasmids, linearized with Spe I, were agarose gel purified and used as standards in QPCR. QPCR for ELF was conducted using a primer pair (150 nM forward
5'-AATCCTGAAGCCTGGTATGGTGGT- $3^{\prime}$ and $100 \mathrm{nM}$ reverse 5'-ACGTTGAAGCCAACATTGTCACCG-3') nested within the $1163 \mathrm{bp}$ ELF fragment to generate amplicons of $126 \mathrm{bp}$ after 40 cycles of $95{ }^{\circ} \mathrm{C}(15 \mathrm{~s}), 62^{\circ} \mathrm{C}$ (30 s), and $72{ }^{\circ} \mathrm{C} \mathrm{(30} \mathrm{s)} \mathrm{and} \mathrm{melting} \mathrm{curve} \mathrm{analysis} \mathrm{on} \mathrm{the}$ Stratagene MX-3000P, as described above. MX-3000P software was again used to generate a standard curve and estimate target gene copy number in each sample.

\section{Image analysis}

Microscope images were captured using a Nikon video camera and analyzed through $\mathrm{NIH}$ Image software (version 1.62) at low power. Starting with a calibration slide, a scale bar length of $100 \mu \mathrm{m}$ was selected. During sample image capture, a field of vision was chosen that had maximum occupancy by oocytes; the scale bar was then pasted into the image and the image stored for analysis at a later time. The calibration slide was repeatedly re-scanned during a photographic session to ensure that the magnification did not change.

For analysis, all intact oocytes in an image were first counted. A proportion of oocytes was then used for data collection; thus, only the largest oocytes $(20 \%$ of total number) were selected to eliminate those oocytes that may have been sectioned off-center. To find these oocytes, the largest $25 \%$ of oocytes (by eye) were numbered and oocyte areas were measured by $\mathrm{NIH}$ image software. Oocyte diameters were subsequently calculated by taking the square root of oocyte surface area and multiplying this value by $4 / \pi$. Data were then sorted by oocyte diameter and the largest $80 \%$ (i.e. $20 \%$ total oocytes) retained and means calculated to yield a single value for each image, thereby avoiding pseudoreplication. As much as possible, all images from any one experiment were analyzed by the same operator.

\section{Validation of image analysis}

The procedures outlined above were applied independently (1 month apart; no communication on result, etc.) by two different authors (PML, KANG) to the 0 and $30 \mathrm{ng} / \mathrm{ml}$ rhIGF-I samples of Trial IV to assess reliability and consistency of oocyte diameter measurements. We extended the validations by comparing the same two treatments after counting not only the largest $20 \%$, but also the largest $10 \%$ and largest $40 \%$ during image analysis.

\section{Statistical analysis}

Figures were primarily drawn on the basis of the percentage change (mean \pm s.E.M.) of response variables to circumvent the large error bars that otherwise result due to fish-to-fish variation, obscuring treatment effects. Accordingly, controls were given arbitrary values of ' 1 '. 
Replicates from the same animal were averaged for graphical presentation, but not for statistical analyses.

Statistically, animal-to-animal variation was controlled for by including animal as a random variable into the model. Thus, effects of hormone treatment on oocyte diameter, nuclear diameter, AR abundance, or lipid accumulation in replicated experiments were tested using a nested univariate model in SPSS 14.0 (SPSS Inc., Chicago, IL, USA), command UNIANOVA, with FISH and REPLICATE as random variables and using the following design subcommand:/DESIGN HORMONE FISH(HORMONE) REPLICATE(FISH). To compare the effects of 11-KT and E2, a two-way univariate ANOVA was run without the zero dose and without interaction in the model.

Experiments that were run in singles were analyzed using hormone treatment as fixed factor and FISH as random factor in a two- or three-way UNIANOVA/ DESIGN HORMONE_1 HORMONE_2 HORMONE_1*HORMONE_2 FISH. Interaction between hormone treatments was removed from the model if its effect was not significant. Nesting of fish within hormone treatment could not be done due to insufficient degrees of freedom. Normality of data was confirmed by analyzing the spread of residuals, whereas homogeneity of variances was tested on unnested data using Levene's statistic. Posthoc comparisons of means were done using Tukey. Differences between groups were considered significant for $P<0.05$.

\section{Results}

\section{Culture conditions}

Tissues could be maintained in vitro without bacterial or fungal contamination. Histologically, atresia was evident in some oocytes in many of the tissue explants, but the incidence of atresia was not quantified. Some shrinkage of oocytes was noted after processing of explants for histology, especially in paraffin-embedded material, for which no corrections were made. Oocytes from all animals were of comparable size and typically in the range of $50-100 \mu \mathrm{m}$. Due to the small size of the explants used for incubation, together with the regular changes of the incubation medium, some tissue could either not be recovered, or in rare circumstances, proved to be connective tissue. Variation in sample size during analyses could therefore not be avoided.

\section{Validation}

Analyses of images by two independent investigators yielded highly consistent results, as illustrated by regression analysis (Fig. 1). However, a consistent difference between operators in absolute oocyte diameters existed, due to differences in the total number of oocytes counted on a section. These differences were

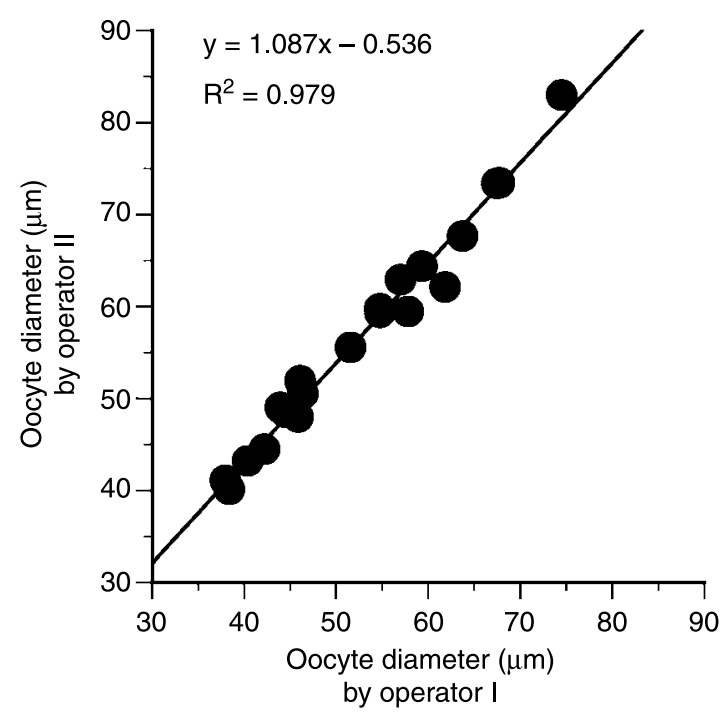

Figure 1 Reliability of measurements on oocyte diameters in eel explants $(n=20)$ by two independent operators.

found to reflect inclusion of the smallest oocytes by one, but not the other operator. As a result, the average oocyte diameter of a sample (based on the 20\% largest oocytes in a section) decreased with increasing numbers of total oocytes, thus yielding oocytes that on average were 7$8 \%$ smaller in diameter. These differences between operators did not affect the statistical outcome, both treatments yielding similar mean diameters that tended to be higher for explants treated with $30 \mathrm{ng} / \mathrm{ml}$ rhlGF-I than for controls (Operator I, $P=0.144$; Operator II, $P=$ 0.065).

Similarly, basing the average oocyte diameter in a section on counting the largest 10,20 , or $40 \%$ in a section did not affect the outcome of the statistical analysis, with rhIGF-I at $30 \mathrm{ng} / \mathrm{ml}$ always tending to yield larger oocyte diameters than controls (all $P>0.05$; data not shown).

\section{Experiment I}

Trial IA

Treatment of ovarian fragments with 11-KT resulted in a significant increase in the diameter of eel oocytes $\left(F_{4,8}=6.803 ; P=0.011\right)$ at all doses, except $10 \mathrm{ng} / \mathrm{ml}$ $(P=0.052$ for this group; data not shown). No differences in oocyte diameter were found among any of the 11-KT treatments. Similarly, there were no significant differences between individual fish, but replicates did differ significantly for some fish $\times$ dose combinations $\left(F_{3,12}=7.151 ; P=0.005\right)$.

\section{Trial IB}

Following 18 days of organ culture, oocyte diameters $\left(F_{1,50}=21.53 ; \quad P<0.001\right)$ and nuclear diameters 

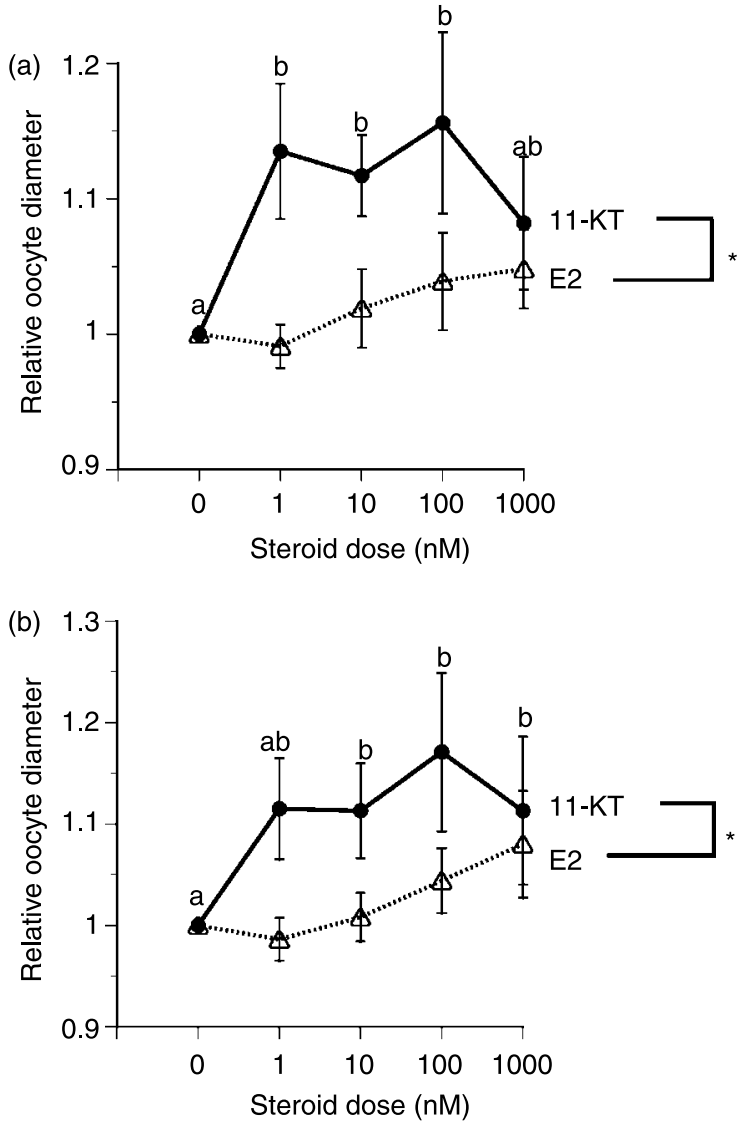

Figure 2 Mean relative oocyte (a) and nuclear diameters (b) after incubation of ovarian fragments from eel (Anguilla australis) in the presence of 0-1000 nM 11-ketotestosterone (11-KT) or estradiol-17 $\beta$ (E2). Steroid effects were significant $\left(^{*}\right)$. Letters above bars indicate statistically different oocyte diameters between doses within steroid treatment. Values are mean \pm s.E.M. of 4-5 fish.

$\left(F_{1,50}=20.164 ; P<0.001\right)$ were significantly greater, by nearly $10 \%$, in cultures containing $11-\mathrm{KT}$ compared with those with E2 added (Fig. 2a and b). Treatment with E2 did not significantly alter oocyte or nuclear diameters. By contrast, 11-KT effects were dose dependent (Fig. 2a and $b)$, and differed significantly from control incubations, except for nuclear diameters of oocytes exposed to $10 \mathrm{nM}$ and for diameters of oocytes exposed to $1000 \mathrm{nM}$.

\section{Trial IC}

Application of protocols for use in transmission electron microscopy (TEM) yielded trends for $11-\mathrm{KT}$ that confirmed those obtained by tissues processed for paraffin (Trial I) or methacrylate resin embedding (Trial II), even with a small sample size of three fish. Thus, treatment of ovarian fragments with 11-KT led to a dosedependent increase in relative oocyte diameters, which was significant in the physiological range (10 and $100 \mathrm{nM}$ ) when compared with control incubations (data not shown). Histologically, ovaries from all females were in the early stages of lipid accumulation and had maximum oocyte diameters ranging between 50 and $70 \mu \mathrm{m}$. Effects of $11-\mathrm{KT}$ on oocyte size were readily visible (cf. Fig. 3a and b). However, the increase in diameter brought about by 11-KT were neither reflected in obvious changes in number of lipid droplets nor in mitochondrial number or Golgi apparatus, at least not when comparing explants exposed to 0 and $100 \mathrm{nM}$ 11-KT (Fig. 3c and d). Atresia (Fig. 3e) and oogonia (Fig. 3f) were occasionally found in ultrathin sections.

\section{Experiment II}

\section{Trial IIA}

Growth factors, rather than pituitary hormones, tended to affect oocyte diameters in vitro. Thus, addition of oGH had no effect $\left(F_{3,12}=1.374 ; P=0.298\right)$, whereas only hCG at $1 \mathrm{IU} / \mathrm{ml}$ resulted in a significantly smaller oocyte diameter compared with other doses after 18 days of culture $\left(F_{3,12.3}=3.562 ; P=0.047\right)$. In contrast, rhlGF-I induced a highly significant increase in oocyte diameters $\left(F_{3,12.3}=6.434 ; P=0.007\right)$, essentially in a doseresponse fashion (Fig. 4a). Similarly, pINS significantly affected oocyte size $\left(F_{3,12.6}=7.752 ; P=0.003\right)$, although a dose response was not apparent. Differences between fish were not significant for any of the treatments.

\section{Trial IIB}

Responses of ovarian explants to rhIGF-I varied considerably between the three individuals, and a significant treatment effect therefore could not be discerned $(P=0.593)$. However, there was a tendency for oocyte diameters to increase with increasing dose of IGF-I (data not shown).

\section{Trial IIIC}

Exposure of ovarian explants to IGF-I resulted in a highly significant increase $\left(F_{4,50}=6.974 ; P=0.011\right)$ in oocyte diameters in an approximately dose-dependent fashion (Fig. 4b). Oocyte diameters of ovarian follicles exposed to control media or those containing $1 \mathrm{ng} / \mathrm{ml}$ IGF-I averaged $70 \mu \mathrm{m}$ in diameter, increasing to mean values of up to $92 \mu \mathrm{m}$ in the highest dose IGF-I groups. Effects of 11-KT were additive and also highly significant $\left(F_{1,50}=4.157 ; P=0.006\right)$, and the steroid increased mean oocyte diameters from 76 to $87 \mu \mathrm{m}$ across treatment groups.

\section{Experiment III: in vitro effects of leptin on eel ovarian fragments}

\section{Trial IIIA, $B$}

Leptin did not affect oocyte diameters in either trial (IIIA: $F_{2,29}=0.527 ; P=0.717 ;$ IIIA: $F_{4,55}=0.177 ; P=0.949$; 

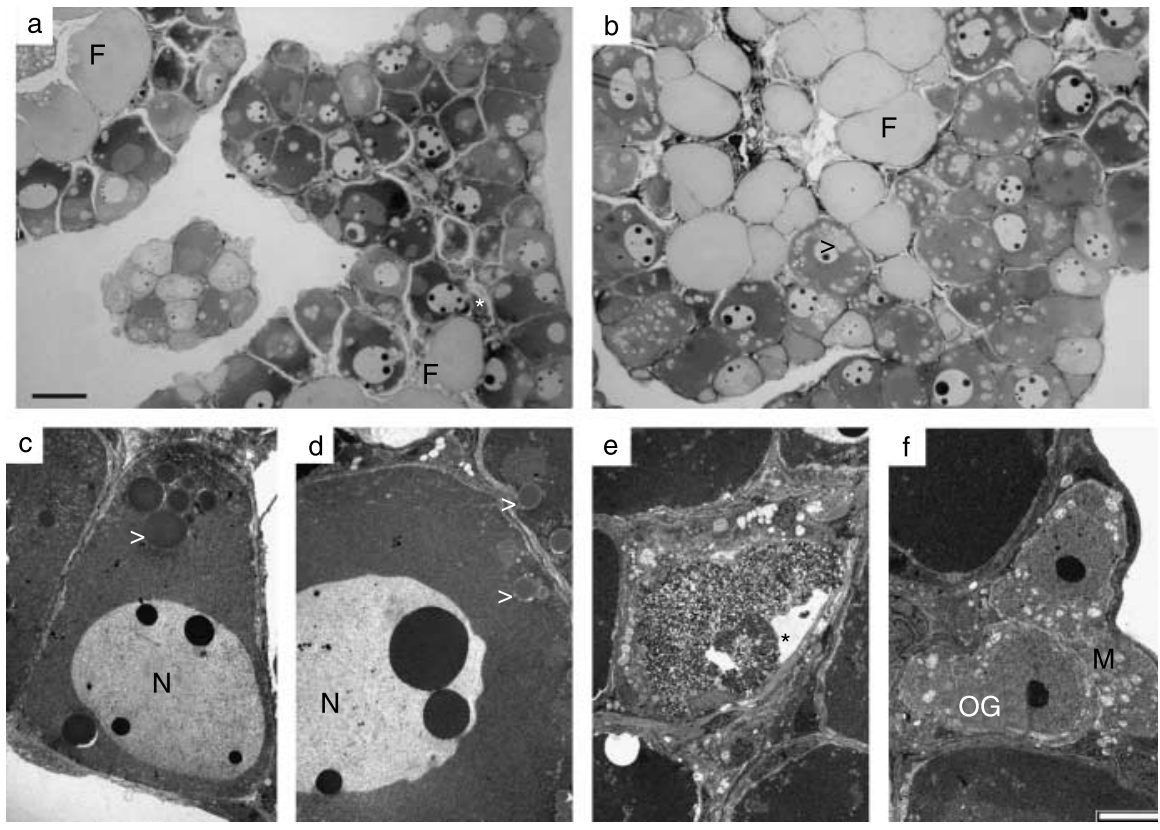

Figure 3 Micrographs of ovarian tissue from eel (Anguilla australis; explants a-d are from the same female) treated in vitro with $0(\mathrm{a}, \mathrm{c}$, e and f) or $100 \mathrm{nM} 11-\mathrm{KT}$ (b, d) for 18 days. Note the presence of larger oocytes after exposure with $100 \mathrm{nM} 11-\mathrm{KT}$ (b), but the absence of any clear changes in ultrastructure (d). Some atretic oocytes (e) as well as oogonia (f) were present. Abbreviations and symbols: $\mathrm{N}$, nucleus; $\mathrm{F}$, fat; $>$, lipid droplet; *, atretic oocyte; OG, oogonium; M, mitochondrion. Scale bar light micrographs, $50 \mu \mathrm{m}$; scale bar electron micrographs, $5 \mu \mathrm{m}$ (f) or $10 \mu \mathrm{m}$ (c-e). data not shown). Effects of $11-\mathrm{KT}$ were significant only for trial IIIA ( $F_{1,29}=16.767 ; P<0.001$; data not shown).

\section{Experiment IV: effects of lipid supplementation on 11-KT-stimulated oocyte growth in vitro}

\section{Trial IVA In vitro accumulation of lipids}

Addition of lipids to the incubation medium tended to result in increased oocyte diameters $\left(F_{2,26}=2.393\right.$; $P=0.111)$. Indeed, for six out of seven females, control incubations yielded the smallest oocyte diameters. Oocyte diameters for the control incubation from the seventh fish were unusual, at nearly twice those seen for some other incubations; exclusion of this single data point changed the probability for an effect of lipid addition on oocyte diameters to $P=0.003$ with an average increase of $14 \mu \mathrm{m}$ to the oocyte diameter in response to adding PL or FAS (Fig. 5). Regardless of whether the outlying data point was included or excluded, a statistically significant additive effect of $11-\mathrm{KT}$ was observed $\left(F_{1,26}=9.349 ; P<0.001\right.$; Fig. 5).

\section{Trial IVB In vitro accumulation of ${ }^{14} \mathrm{C}$-triolein}

Accumulation of ${ }^{14} \mathrm{C}$-triolein in ovarian fragments was significantly increased (Fig. 6a and b) in the presence of $11-\mathrm{KT}\left(F_{1,13.1}=6.587 ; P=0.023\right)$, but not $\mathrm{FSH}\left(F_{1,13.2}=\right.$ 1.688; $P=0.216$ ), when analyzing data from both days in the same nested ANOVA. Statistical outcome was regardless of whether the non-significant interaction term $(11-\mathrm{KT} * \mathrm{FSH})$ was included in the model. Duration of incubation also significantly increased triolein accumulation in ovarian fragments $\left(F_{1,52}=50.242 ; P<0.001\right)$.
When simplifying the statistical model and analyzing data for both days individually, degrees of freedom were insufficient to detect an effect of $11-\mathrm{KT}$ by 1 day $\left(F_{1,13}=1.912 ; P=0.19\right)$ and just insufficient to detect an $11-\mathrm{KT}$ effect by 4 days of incubation $\left(F_{1,14.3}=4.464\right.$; $P=0.053)$.

\section{Experiment $V$ : in vitro effects of 11-KT on ovarian AR gene expression}

AR transcript abundance was low, with maximum levels of around 7000 and 1700 copies/ $\mu$ g total RNA for AR $\alpha$ and $A R \beta$ respectively. QPCR on total RNA without the RT step typically yielded 500-2000 copies of target/ $\mu$ g RNA. There was insufficient RNA to assess contamination of cDNA for all samples; an arbitrary threshold of 2000 copies of target/ $\mu$ g RNA was therefore set as the minimum detectable level, deeming AR $\beta$ mRNA levels undetectable in all samples. Samples in which AR $\alpha$ copy

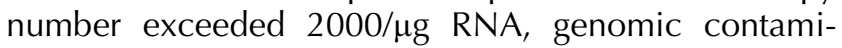
nation copy number was subtracted if a value for that sample could be obtained; in the absence of an estimate of copy number due to genomic contamination, the copy number was set at 1000, midway in the contamination range (500-2000 copies). Estimates for AR $\alpha$ copy number could accordingly be obtained for 11 out of 25 samples. Although insufficient for statistical analysis, data on $A R \alpha$ transcript abundance from only these 11 samples hinted at a reduction in copy number with increasing concentrations of $11-\mathrm{KT}$ in the incubation medium, regardless of whether the data were expressed per microgram total RNA or per $10^{6}$ copies of ELF (Fig. 7a and b). 
(a)
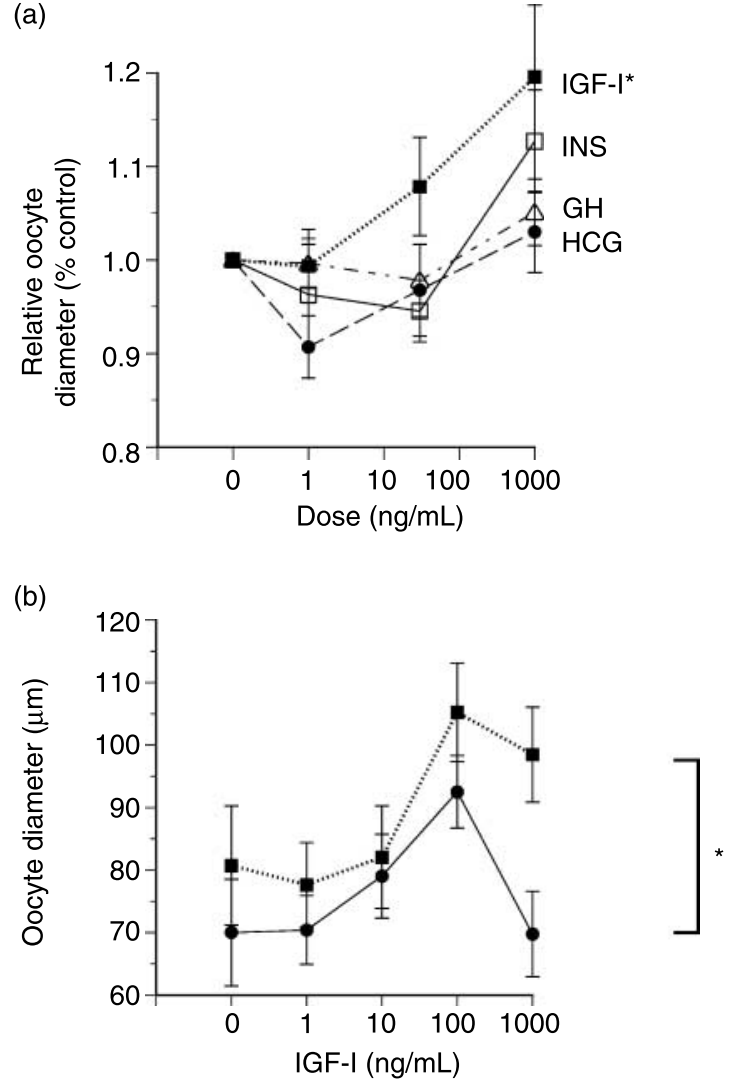

Figure 4 Relative diameter of oocytes after incubation of ovarian fragments from eel (Anguilla australis) with 0, 1, 30, or $1000 \mathrm{ng} / \mathrm{ml}$ recombinant human insulin-like growth factor-I (rhIGF-I), porcine insulin (pINS), ovine growth hormone $(\mathrm{oGH})$, or human chorionic gonadotropin (hCG) (a), or with $0-1000 \mathrm{ng} / \mathrm{ml}$ rhIGF-I in the presence or absence of $100 \mathrm{nM} 11$-ketotestosterone (b). Explants treated with rhIGF-I had significantly greater mean oocyte diameters $(*)$ than remaining treatments, and its effects were dose dependent $(P<0.05)$. Values are mean \pm s.E.M. of 4-5 fish.

\section{Discussion}

Since little is known about the factors controlling previtellogenic growth in teleost fish other than two early reports (Remacle et al. 1976, Khoo 1979), we exposed eel ovarian fragments to a range of hormones in vitro. Exposure to $\mathrm{E} 2$ did not affect oocyte diameter after 18 days of culture. Remacle et al. (1976) likewise could not detect any effects of estrogens on the goldfish ovary in vitro, irrespective of oocyte stage. In vivo observations, however, seem contradictory; Yu et al. (1979), while feeding estrogen-enriched diets, could not detect any effect on perinucleolar oocytes in ovaries of juvenile coho salmon. In contrast, E2 treatment was correlated with cortical alveolus formation in hypophysectomized goldfish (Khoo 1979). In European silver eels, oocytes increased from an average of around $70 \mu \mathrm{m}$ in controls (previtellogenic) to around $180 \mu \mathrm{m}$ (very early vitellogenic) after long-term in vivo E2-treatment (Olivereau \& Olivereau 1979). This increase coincided with an increase in accumulated lipids. However, the

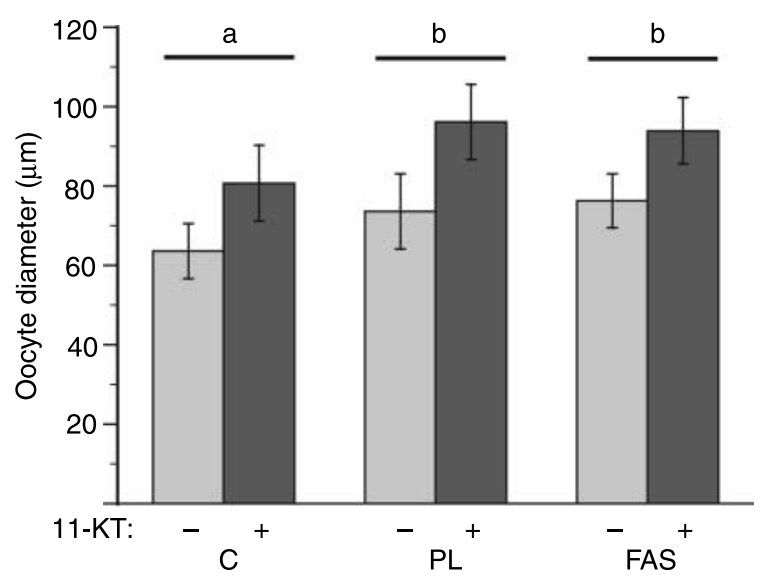

Figure 5 Diameter of oocytes after incubation of ovarian fragments from eel (Anguilla australis) under control conditions (C) or after addition of $100 \mu \mathrm{g} / \mathrm{ml}$ phospholipid (PL; 1,2-diacyl-sn-glycero-3-phosphocholine, Sigma Chemical Co.) or a fatty acid supplement (FAS) containing $60 \mathrm{ng} / \mathrm{ml}$ linoleic acid $+30 \mathrm{ng} / \mathrm{ml}$ oleic acid. Incubations were done with or without addition of $100 \mathrm{nM} 11$-ketotestosterone (11-KT). Bars represent the mean $\pm>$ S.E.M. of 5-7 fish. Differences between lipid supplements are indicated by differing letters above bars $(P<0.05)$. $11-\mathrm{KT}$ effects were significant $(P<0.001)$.

profound increase in the activity of gonadotropes suggests that the observed gonadal changes are not only attributable to E2 but probably also to gonadotropins.

In contrast to E2, in vitro treatment of eel ovarian fragments with 11-KT led to a significant increase in the size of the largest oocytes in all the three trials, irrespective of the method of tissue processing used (paraffin, methacrylate, epoxy resin). The nucleus too, appeared to be larger in oocytes from explants treated with 11-KT, an effect that was confirmed statistically for Trial IB. Ultrastructurally, increased oocyte dimensions were not mirrored by notable changes in cell morphology other than a seemingly larger nucleus (Trial IC); thus, oocytes were recognizably larger when viewed with the electron microscope, but there was no clear evidence for the increased abundance of organelles, such as endoplasmic reticulum or golgi. Similarly, mitochondrial numbers were not clearly altered, although the non-random distribution of mitochondria makes it difficult to ascertain this conclusively. Likewise, there were no histological or ultrastructural indications that the abundance of lipid droplets in the ooplasm had changed. This is not in keeping with the observed lipid accumulation following exposure of eels to 11-KT in vivo (Rohr et al. 2001) or with the uptake of lipids in the form of radiolabeled triglycerides into the ovary that was stimulated by 11-KT (Expt IVb). These observations, together with the finding that the addition of lipid supplements to the incubation medium tended to increase oocyte diameters in the presence of 11-KT (Expt IVa), suggest that lipids were limited in the medium, thus prohibiting ultrastructural change (Trial IC).

Remacle et al. (1976) previously investigated the effect of different hormone preparations on vitellogenic 

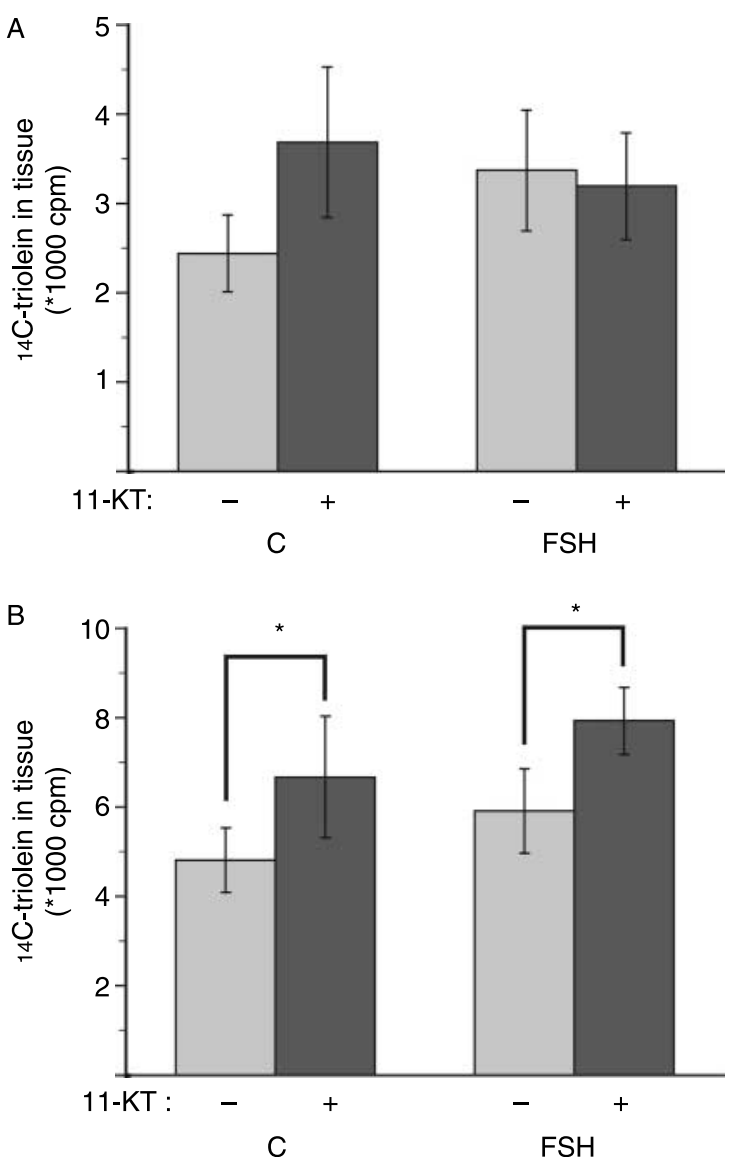

Figure 6 Accumulation of ${ }^{14} \mathrm{C}$-triolein in ovarian fragments of eel (Anguilla australis) incubated for 1 (a) or 4 days (b) under control conditions $(\mathrm{C})$ or in the presence of $100 \mathrm{ng} / \mathrm{ml}$ salmon folliclestimulating hormone (FSH). Incubations were done with or without addition of $100 \mathrm{nM} 11$-ketotestosterone (11-KT). Bars represent the mean \pm S.E.M. of five fish. Differences between treatments are indicated by asterisks above bars $(P<0.05)$.

ovarian tissues of goldfish in vitro. Interestingly, the integrity of oocytes up to stage IV (cortical alveolus stage) was better in the presence of testosterone and somatic tissues were less hypertrophied when compared with controls. The authors further suspected the development of nests of spermatogonia within the ovarian explants (Remacle et al. 1976). In our study, the presence of nests of spermatogonia was not apparent.

Androgens have been implicated in oogenesis in mammals, particularly in the growth of small preantral follicles. These follicles resemble previtellogenic follicles of fishes in that growth progresses slowly, occurs both prior to and after puberty (McGee \& Hsueh 2000) and appears to be mostly gonadotropin independent (reviewed by Smitz \& Cortvrindt 2002). Thus, the number of primordial follicles advancing to the pre- or small antral stage increased in androgen-treated monkeys (Vendola et al. 1998, 1999a). Likewise, women treated with testosterone or suffering from androgen excess (polycystic ovarian syndrome, androgen-
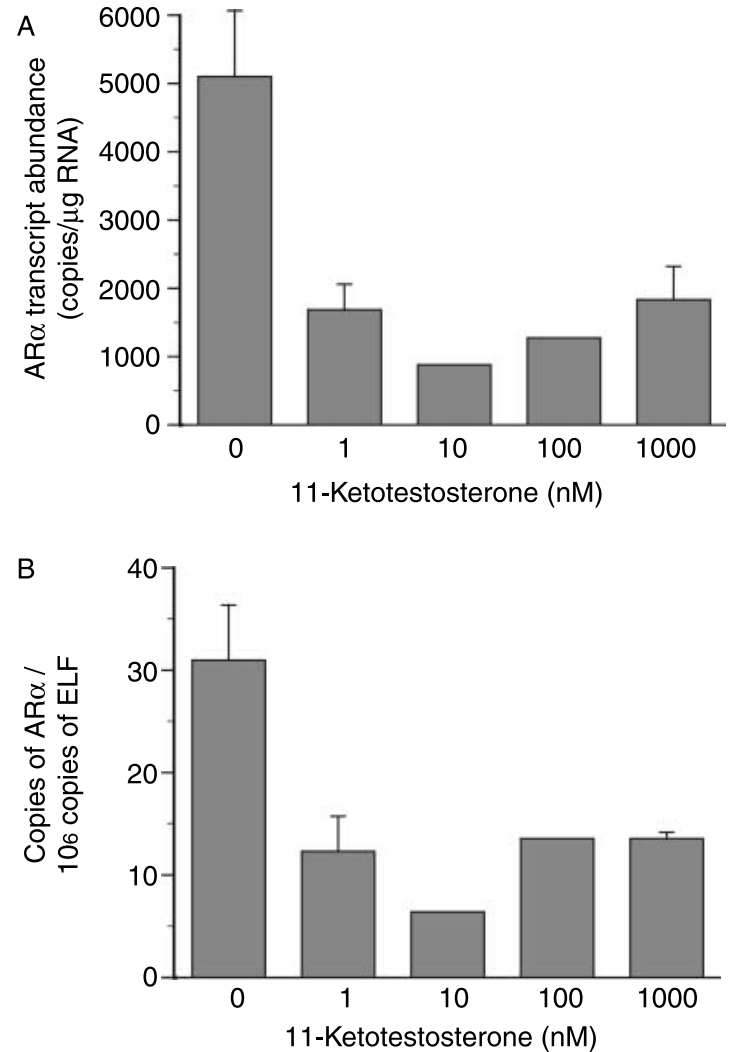

Figure 7 Effects of 11-ketotestosterone $(0-1000 \mathrm{nM})$ on androgen receptor- $\alpha$ (AR $\alpha$ ) mRNA copy number (a) or after normalizing over elongation factor (ELF; b) in ovarian explants of eel after 18 days of incubation in vitro. Sample sizes were 3, 4, 1, 1, and 2 for 0-1000 nM doses respectively. Statistical analyses were not carried out due to small sample sizes.

producing tumors) showed increased numbers of growing follicles (reviewed in Vendola et al. 1998). These observations contrast with atretogenic actions of androgens on preantral follicles in immature hypophysectomized rats (Hillier 1987). Although some of the stimulatory effects may be indirect, via surrounding stromal tissue (Vendola et al. 1999a), direct androgen effects on ovarian follicles are likely given that AR mRNA abundance in rhesus monkey was the greatest in preantral to small antral follicles (Weil et al. 1998). In the mouse, a role for androgens is also apparent in view of the observations that female AR knock-outs had reduced average litter size (Yeh et al. 2002, Shiina et al. 2006) and an increased incidence of atresia of ovarian follicles (Shiina et al. 2006). The latter observations probably result from impaired folliculogenesis, as evidence has recently been mounting for an important role of androgens in folliculogenesis through modulation of expression or effects of local growth factors (e.g., Hickey et al. 2005, Shiina et al. 2006).

In our previous in vivo work on shortfinned eels (Rohr et al. 2001), 11-KT had a clear effect on the growth of previtellogenic oocytes, but it was not determined 
whether this was a direct or an indirect effect, mediated via feedback of this steroid on the brain-pituitary axis. The current findings, based around an in vitro bioassay design, comply with the mammalian scenario, and indicate that at least some of the effects seen in vivo are likely to have been direct. The presence of $A R$ $m R N A$, but not AR $\beta$ mRNA, in the eel ovary, albeit at copy numbers some $2-5$ fold lower for the $\alpha$-subtype than those seen in vivo (M Algie and PM Lokman, unpublished observations), or around 20-50 fold lower than those reported in for example, liver or muscle of melengestrol acetate-treated heifers (Pfaffl et al. 2002), support this notion. In other species of fish, such as coho salmon (Fitzpatrick et al. 1994), Atlantic croaker, Micropogonias undulatus (Sperry \& Thomas 1999), seabream, Pagrus major (Touhata et al. 1999), goldfish (Wells \& Van Der Kraak 2000), and Japanese eel (Ikeuchi et al. 1999), AR transcripts have also been identified in the ovary. However, specific roles of androgens and ARs in the fish ovary have not been described previously, and this is the first study to indicate a possible function, i.e. involvement in control of previtellogenic oocyte growth, at least in eel.

Maximal effects of 11-KT were observed when using doses in the $10-100 \mathrm{nM}$ range $(3-30 \mathrm{ng} / \mathrm{ml})$, similar to blood 11-KT levels seen in very early vitellogenic shortfinned eels caught from the wild $(20-50 \mathrm{ng} / \mathrm{ml}$; Lokman et al. 1998, 2002). Although not a focal point of other investigations, increased levels of androgens (generally testosterone, rather than 11-KT) during previtellogenesis have been reported in a number of fish species, such as striped bass, Morone saxatilis (Holland et al. 2000) and seahorse, Hippocampus abdominalis (Poortenaar et al. 2004). In females of other species, such as killifish, Fundulus grandis (Greeley et al. 1988), channel catfish, Ictalurus punctatus (Kumar et al. 2000) and sweep, Scorpis lineolatus (Dedual \& Pankhurst 1992), elevated androgen levels during previtellogenesis were not obvious. Nonetheless, it is likely that androgens do not only serve as precursors for estrogen synthesis, but also that they have a functional role during previtellogenesis in teleost fish in general.

Completion of the previtellogenic growth phase in fish is followed, at some stage, by initiation of puberty, the activation of the brain-pituitary-gonad axis. In eels, puberty coincides, or is just preceded by, 'silvering'; silvering encompasses dramatic changes in the physiology and behavior of the eel in preparation for a longdistance oceanic migration and is probably mediated by 11-KT (Rohr et al. 2001, Lokman et al. 2002). Pre-adaptations include increases in eye size, expression of different opsins, jaw remodeling for stream-lining, cardiovascular changes, cessation of feeding, and enhancement of hypo-osmoregulatory ability (reviewed in Lokman et al. 2003 b). It is believed that silvering only occurs once eels reach a critical condition (fat stores;
Larsson et al. 1990). Therefore, it is likely that hormones involved in metabolism and growth modify the activity of the brain-pituitary-gonad axis. However, it is not clear which metabolic hormone is the primary regulator of this axis, and there is no evidence to indicate at which level the axis is most affected. When evaluating the effects of heterologous peptide hormones, namely, gonadotropin, growth hormone, insulin, IGF-I and leptin on the eel ovary in vitro, an effect was noted only for IGF-I. It is possible that heterologous hormones were not recognized by the previtellogenic eel ovary, an issue that is impossible to address without extensive research on receptor-ligand interaction for these peptides. Such data is fortunately available for IGF, a structurally highly conserved protein for which the salmon and human recombinant homologs have comparable activities in salmon embryonic cells in vitro (Upton et al. 1998). Addition of hIGF-I to the incubation medium resulted in a significant increase in eel oocyte diameters, an effect that was additive to that of $11-\mathrm{KT}$. In the mammalian ovary, IGF-I appears to be important for oogenesis throughout the development of the ovarian follicle. For example, IGF-I can modify ovarian steroidogenesis, and thus appears to play a role in dominant follicle selection (Ginther et al. 2004). Similarly, IGF-I can increase the population of gonadotropin-independent small antral follicles (Gong et al. 1997) and stimulate growth of preantral follicles, possibly through mediating androgen action (Vendola et al. 1999a, 1999b). Wide effects of IGF-I on aspects of oogenesis have been reported in fish also; thus, IGF-I can affect basal or gonadotropinsupported steroidogenesis in vitellogenic or maturing ovarian follicles (Weber \& Sullivan 2000, Mendez et al. 2005), and IGFs have been implicated in stimulating germinal vesicle breakdown in a number of fish species (e.g., Weber \& Sullivan 2000). Very recently, involvement of IGF-I on early stages of oogenesis in salmon was postulated on the basis of its plasma dynamics during previtellogenesis (Campbell et al. 2006). Our findings on the eel ovary confirm an involvement in regulating previtellogenic ovarian growth, although the mechanisms that cause actual growth remain to be established.

Noticeable animal-to-animal variation in responses to hormones was observed in our experiments, although responses obtained were consistent among trials, and did not depend on the individual investigator, on the tissue processing technique, or on the number of oocytes measured. Therefore, individual variation cannot be attributed to methodology or data analysis. Instead, there probably is a physiological cause for the differences amongst individuals, for instance in relation to differences in IGF-I receptor and AR abundance, issues that require additional study.

In summary, we have shown using a functional in vitro organ culture system that IGF-I and the androgen 11-KT can exert direct effects on the eel ovary, resulting in 
additive increases in size of previtellogenic oocytes. Moreover, 11-KT, but not FSH, significantly stimulated the accumulation of radiolabeled triglycerides into the ovary. We conclude that growth factors and androgens are involved in the regulation of previtellogenic oocyte growth in a teleost fish.

\section{Acknowledgements}

We gratefully acknowledge the help from Matthew Downes and Karen Judge, (Department of Zoology) with sample processing, and help from Ken Miller (Department of Zoology) to prepare the figures for publication. Thank you to Jamie McQuillan (Department of Zoology) and Dr Hajime Matsubara (National Institute of Aquaculture, Mie, Japan) for help with real-time PCR and cloning of ELF respectively. We are also grateful to Dr Peter Lee (NIWA) for the gift of captive-reared eels for experimentation and to students Emma Howell, Bryony McNeill, and Sandra Soeder-Hunua for their assistance with image processing. We thank Dr Penny Swanson (Northwest Fisheries Science Center) for the gift of coho salmon FSH, and the National Hormone and Pituitary Program of the NIDDK $(\mathrm{NIH}$, Baltimore, MD, USA) for the gift of oGH. This paper is dedicated to our dear colleague Gerald Stokes, who for many years has been our beacon for histological assistance and advice, but passed away on 19 December, 2003. This study was supported by a grant from the University of Otago Research Committee (PML 2003; 2004). A small part of this study has been previously published in the form of conference proceedings in Fish Physiology \& Biochemistry, Volume 28, 283-285 (2003). The authors declare that there is no conflict of interest that would prejudice the impartiality of this scientific work.

\section{References}

Campbell B, Dickey J, Beckman B, Young G, Pierce A, Fukada H \& Swanson P 2006 Previtellogenic oocyte growth in salmon: relationships among body growth, plasma insulin-like growth factor-1, estradiol-17 $\beta$, follicle-stimulating hormone and expression of ovarian genes for insulin-like growth factors, steroidogenic-acute regulatory protein and receptors for gonadotropins, growth hormone and somatolactin. Biology of Reproduction 75 34-44.

Dedual M \& Pankhurst NW 1992 Plasma steroid hormone concentrations in relation to the reproductive cycle of the sweep Scorpis lineolatus (Kyphosidae) caught from the wild. Australian Journal of Marine and Freshwater Research 43 753-763.

Fitzpatrick MS, Gale WL \& Schreck CB 1994 Binding characteristics of an androgen receptor in the ovaries of coho salmon Oncorhynchus kisutch. General and Comparative Endocrinology 95 399-408.

Fontaine YA, Lopez E, Delerue-Le Belle N, Fontaine-Bertrand E, Lallier F \& Salmon C 1976 Stimulation gonadotrope de l'ovaire chez I'anguille (Anguilla anguilla L.) hypophysectomisée. Journal de Physiologie 72 871-892.

Fortune JE, Cushman RA, Wahl CM \& Kito S 2000 The primordial to primary follicle transition. Molecular and Cellular Endocrinology $16353-60$.

Ginther OJ, Bergfelt DR, Beg MA, Meira C \& Kot K 2004 In vivo effects of an intrafollicular injection of insulin-like growth factor 1 on the mechanism of follicle deviation in heifers and mares. Biology of Reproduction 70 99-105.
Gong JG, Baxter G, Bramley TA \& Webb R 1997 Enhancement of ovarian follicle development in heifers by treatment with recombinant bovine somatotropin: a dose-response study. Journal of Reproduction and Fertility 110 91-99.

Greeley MS, MacGregor R \& Marion KR 1988 Variation in plasma estrogens and androgens during the seasonal and semilunar spawning cycles of female gulf killifish, Fundulus grandis (Baird and Girard). Journal of Fish Biology 33 419-429.

Hickey TE, Marrocco DL, Amato F, Ritter LJ, Norman RJ, Gilchrist RB \& Armstrong DT 2005 Androgens augment the mitogenic effects of oocyte-secreted factors and growth differentiation factor 9 on porcine granulosa cells. Biology of Reproduction 73 825-832.

Higashino T, Miura T, Miura C \& Yamauchi K 2003 Effects of two sex steroid hormones on early oogenesis in Japanese huchen (Hucho perryi). Fish Physiology and Biochemistry 28 343-344.

Hillier SG 1987 Intrafollicular paracrine function of ovarian androgen. Journal of Steroid Biochemistry 27 351-357.

Holland CM, Hassin S \& Zohar Y 2000 Gonadal development and plasma steroid levels during pubertal development in captive-reared striped bass, Morone saxatilis. Journal of Experimental Zoology 286 49-63.

Ikeuchi T, Todo T, Kobayashi T \& Nagahama Y 1999 cDNA cloning of a novel androgen receptor subtype. Journal of Biological Chemistry 274 25205-25209.

Kezele PR, Nilsson EE \& Skinner MK 2002 Insulin but not insulin-like growth factor-1 promotes the primordial to primary follicle transition. Molecular and Cellular Endocrinology 192 37-43.

Khoo KH 1979 The histochemistry and endocrine control of vitellogenesis in goldfish ovaries. Canadian Journal of Zoology $\mathbf{5 7}$ 617-626.

Kumar RS, ljiri S \& Trant JM 2000 Changes in the expression of genes encoding steroidogenic enzymes in the channel catfish (Ictalurus punctatus) ovary throughout a reproductive cycle. Biology of Reproduction 63 1676-1682.

Larsson P, Hamrin S \& Okla L 1990 Fat-content as a factor inducing migratory behavior in the eel (Anguilla anguilla L) to the Sargasso Sea. Die Naturwissenschaften 77 488-490.

Lokman PM, Vermeulen GJ, Lambert JGD \& Young G 1998 Gonad histology and plasma steroid profiles in wild New Zealand freshwater eels (Anguilla dieffenbachii and A. australis) before and at the onset of the natural spawning migration. I. Females. Fish Physiology and Biochemistry 19 325-338.

Lokman PM, Harris B, Kusakabe M, Kime DE, Schulz RW, Adachi S \& Young G 2002 11-Oxygenated androgens in female teleosts: prevalence, abundance and life history implications. General and Comparative Endocrinology 129 1-12.

Lokman PM, Rohr DH, Davie PS \& Young G 2003 The physiology of silvering in anguillid eels - androgens and control of metamorphosis from the yellow to the silver stage. In Advances in Eel Biology, pp 331-349. Eds K Aida, K Tsukamoto \& K Yamauchi. Tokyo: Springer Verlag.

McGee EA \& Hsueh AJW 2000 Initial and cyclic recruitment of ovarian follicles. Endocrine Reviews 21 200-214.

Mendez E, Montserrat N \& Planas JV 2005 Modulation of the steroidogenic activity of luteinizing hormone by insulin and insulin-like growth factor-I through interaction with the cAMPdependent protein kinase signaling pathway in the trout ovary. Molecular and Cellular Endocrinology 229 49-56.

Miura T, Yamauchi K, Takahashi H \& Nagahama Y 1991 Hormonal induction of all stages of spermatogenesis in vitro in the male Japanese eel (Anguilla japonica). PNAS 88 5774-5778.

Nagahama Y, Yoshikuni M, Yamashita M, Tokumoto T \& Katsu Y 1995 Regulation of oocyte growth and maturation in fish. Current Topics in Developmental Biology 30 103-145.

Nilsson EE \& Skinner MK 2002 Growth and differentiation factor-9 stimulates progression of early primary but not primordial rat ovarian follicle development. Biology of Reproduction 67 1018-1024. 
Nilsson E, Parrott JA \& Skinner MK 2001 Basic fibroblast growth factor induces primordial follicle development and initiates folliculogenesis. Molecular and Cellular Endocrinology 175 123-130.

Olivereau M \& Olivereau J 1979 Effect of estradiol-17ß on the cytology of the liver, gonads and pituitary, and on plasma electrolytes in the female freshwater eel. Cell and Tissue Research 199 431-454.

Parrott JA \& Skinner MK 1999 Kit-ligand/stem cell factor induces primordial follicle development and initiates folliculogenesis. Endocrinology $1404262-4271$.

Patiño R \& Sullivan CV 2002 Ovarian follicle growth, maturation, and ovulation in teleost fish. Fish Physiology and Biochemistry 26 57-70.

Pfaffl MW, Daxenberger A, Hageleit M \& Meyer HHD 2002 Effects of synthetic progestagens on the mRNA expression of androgen receptor, progesterone receptor, oestrogen receptor $\alpha$ and $\beta$, insulin-like growth factor-I (IGF-I) and IGF-I receptor in heifer tissues. Journal of Veterinary Medicine A49 57-64.

Poortenaar CW, Woods CMC, James PJ, Giambartolomei FM \& Lokman PM 2004 Reproductive biology of female big-bellied seahorses. Journal of Fish Biology 64 717-725.

Remacle C, Delaere P \& Jacquet P 1976 Actions hormonales sur les cellules germinales femelles de Carassius auratus L., en culture organotypique. Renversement sexuel et ovogenése in vitro. General and Comparative Endocrinology 29 212-224.

Rohr DH, Lokman PM, Davie PS \& Young G 2001 11-Ketotestosterone induces silvering-related changes in immature female short-finned eels, Anguilla australis.. Comparative Biochemistry and Physiology 130A 701-714.

Santos EM, Rand-Weaver M \& Tyler CR 2001 Follicle-stimulating hormone and its $\alpha$ and $\beta$ subunits in rainbow trout (Oncorhynchus mykiss): Purification, characterization, development of specific radioimmunoassays, and their seasonal plasma and pituitary concentrations in females. Biology of Reproduction 65 288-294.

Shiina H, Matsumoto T, Sato T, Igarashi K, Miyamoto J, Takemasa S, Sakari M, Takada T, Nakamura T, Metzger D et al. 2006 Premature ovarian failure in androgen receptor-deficient mice. PNAS 103 224-229.

Smitz JEJ \& Cortvrindt RG 2002 The earliest stages of folliculogenesis in vitro. Reproduction 123 185-202.

Sperry TS \& Thomas P 1999 Characterization of two nuclear androgen receptors in Atlantic croaker: comparison of their biochemical properties and binding specificities. Endocrinology 140 1602-1611.

Sundararaj BI \& Goswami SV 1968 Effect of short- and long-term hypophysectomy on ovary and interrenal of catfish Heteropneustes fossilis (Bloch). Journal of Experimental Zoology 168 85-103.

Touhata K, Kinoshita M, Tokuda Y, Toyohara H, Sakaguchi M, Yokoyama Y \& Yamashita S 1999 Sequence and expression of a cDNA encoding the red seabream androgen receptor. Biochimica et Biophysica Acta 1450 481-485.

Tyler CR, Santos EM \& Prat F 2000 Unscrambling the egg - cellular, biochemical, molecular and endocrine advances in oogenesis. In
Proceedings of the 6th International Symposium on the Reproductive Physiology of Fish, pp 273-280. Eds B Norberg, OS Kjesbu, GL Taranger, E Andersson \& SO Stefansson. Bergen, Norway: Institute of Marine Research and University of Bergen.

Tyler CR \& Sumpter JP 1996 Oocyte growth and development in teleosts. Reviews in Fish Biology and Fisheries 6 287-318.

Upton Z, Yandell CA, Degger BG, Chan SJ, Moriyama S, Francis GL \& Ballard JF 1998 Evolution of insulin-like growth factor-I (IGF-I) action: in vitro characterization of vertebrate IGF-I proteins. Comparative Biochemistry and Physiology 1218 35-41.

Vendola KA, Zhou J, Adesanya OO, Weil SJ \& Bondy CA 1998 Androgens stimulate early stages of follicular growth in primate ovary. Journal of Clinical Investigation 101 2622-2629.

Vendola K, Zhou J, Wang J, Famuyiwa OA, Bievre M \& Bondy CA 1999a Androgens promote oocyte insulin-like growth factor I expression and initiation of follicle development in primate ovary. Biology of Reproduction 61 353-357.

Vendola K, Zhou J, Wang J \& Bondy CA 1999b Androgens promote insulin-like growth factor-I and insulin-like growth factor-I receptor gene expression in the primate ovary. Human Reproduction $\mathbf{1 4}$ 2328-2332.

Weber GM \& Sullivan CV 2000 Effects of insulin-like growth factor-I on in vitro final oocyte maturation and ovarian steroidogenesis in striped bass, Morone saxatilis. Biology of Reproduction 63 1049-1057.

Weil SJ, Vendola K, Zhou J, Adesanya OO, Wang J, Okafor J \& Bondy CA 1998 Androgen receptor gene expression in the primate ovary: cellular localization, regulation, and functional correlations. Journal of Clinical Endocrinology and Metabolism $832479-2485$.

Wells K \& Van Der Kraak G 2000 Differential binding of endogenous steroids and chemicals to androgen receptors in rainbow trout and goldfish. Environmental Toxicology and Chemistry 19 2059-2065.

Yeh S, Tsai MY, Xu Q, Mu XM, Lardy H, Huang KE, Lin H, Yeh SD, Altuwajiri S, Zhou X et al. 2002 Generation and characterization of androgen receptor knockout (ARKO) mice: an in vivo model for the study of androgen functions in selective tissues. PNAS 99 13498-13503.

Yu TC, Sinnhuber RO \& Hendricks JD 1979 Effect of steroid-hormones on the growth of juvenile coho salmon (Oncorhynchus kisutch). Aquaculture 16 351-359.

Received 25 September 2006

First decision 11 December 2006

Revised manuscript received 18 January 2007

Accepted 30 January 2007 